\title{
3' non-translated sequences in Drosophila cyclin B transcripts direct posterior pole accumulation late in oogenesis and peri-nuclear
} association in syncytial embryos

\author{
BRIAN DALBY and DAVID M. GLOVER \\ Cancer Research Campaign Laboratories, Cell Cycle Genetics Group, Department of Biochemistry, The University, Dundee, DD1 4HN, Scotland
}

\section{Summary}

We have characterised forms of the Drosophila cyclin B transcript that differ as a result of a splicing event which removes a nucleotide segment from the $3^{\prime}$ untranslated region. In oogenesis, both cyclin A RNA and a shorter form of the cyclin $B$ transcript are seen in the cells of the germarium that are undergoing mitosis. The shorter cyclin $B$ transcript alone is then detectable in the presumptive oocyte until stages 7-8 of oogenesis. Both cyclin A RNA and a longer form of the cyclin B RNA are then synthesised in the nurse cells during stages 9-11, to be deposited in the oocyte during stages 11-12. These transcripts become evenly distributed throughout the oocyte cytoplasm but, in addition, those of cyclin $B$ become con- centrated at the posterior pole. Examination of the distributions of RNAs transcribed from chimeric cyclin genes indicates that sequences in the $3^{\prime}$ untranslated region of the larger cyclin B RNA are required both for it to become concentrated at the posterior pole and to direct those transcripts in the body of the syncytial embryo to their peri-nuclear localisation. These sequences are disrupted by the splicing event which generates smaller cyclin B transcripts.

Key words: cyclin B, Drosophila, posterior pole, RNA localisation, oogenesis.

\section{Introduction}

The mitotic cyclins, proteins first identified in the eggs of marine invertebrates, are characterised by changes in their abundance during the cell cycle; they accumulate in interphase and are abruptly degraded in mitosis (Evans et al., 1983; Standart et al., 1987; Swenson et al., 1986). Cyclins are required to complex with and thus activate the major cell cycle regulatory protein kinase p34 ${ }^{\mathrm{cdc} 2}$ (Swenson et al., 1987; Draetta et al., 1989; Meijer et al., 1989; Solomon et al., 1990; Parker et al., 1991; Gautier and Maller, 1991). The active kinase complex brings about the phosphorylation of a variety of substrates including histone H1, microtubules, centrosomes and nuclear lamins. These phosphorylation events are among those required for chromosome condensation, organisation of the mitotic spindle and breakdown of the nuclear envelope prior to entry into mitosis (reviewed by Moreno and Nurse, 1990). Inactivation of the p34 ${ }^{\text {cdc2 }}$ kinase is mediated by abrupt degradation of the cyclins. Addition of a cyclin B mRNA encoding a truncated form of the protein, resistant to proteolytic cleavage, prevents exit from mitosis in Xenopus oocyte extract showing that cyclin degradation is necessary for progress through the cell cycle (Murray and Kirschner, 1989; Murray et al., 1989).

p34 $4^{\text {cdc2 }}$ is part of a conserved mechanism that regulates the G2-M transition. Thus, the $c d c 2$ gene product of S.pombe may be functionally replaced by the Saccha romyces cerevisiae, Drosophila or human homologues (Beach et al., 1982; Jimenez et al., 1990; Lehner and O'Farrell, 1990b; Lee and Nurse, 1987). The A and B type cyclin genes are similarly conserved and have been cloned and sequenced from a number of higher eukaryotes including Drosophila, sea urchins, clams, Xenopus and humans (Lehner and O'Farrell, 1989, 1990a; Whitfield et al., 1989; Pines and Hunt, 1987; Swenson et al., 1986; Westendorf et al., 1989; Minshull et al., 1989, 1990; Pines and Hunter, 1989, 1990). A comparison of the cyclin sequences in a wide range of organisms points towards the conservation of the distinct A and B types of cyclin suggesting these molecules have differing roles in the cell cycle. In Drosophila this is supported by the finding that embryos having mutations in the cyclin A gene arrest development in the cell cycles that follow cellularisation, once the maternal contribution to the embryo has been exhausted. Hence cyclin B cannot substitute for cyclin A function (Lehner and O'Farrell, 1989). Examination of the behaviour of cyclin A and B proteins in cellularised Drosophila embryos and larval brains reveals differences in the timing of their accumulation and breakdown (Whitfield et al., 1990). This may reflect the differential timing of the activation of the p34 ${ }^{\mathrm{cdc} 2}$ kinase associated with either cyclin A or cyclin B 
as observed in Xenopus cell-free systems (Minshull et al., 1990). Pines and Hunter (1991) have also found that the two cyclins accumulate in different sub-cellular compartments in mammalian cells. In the syncytial Drosophila embryo, cyclin A appears to shuttle between an association with chromatin and the cytoplasm, whereas cyclin B is localised to the region at which nuclear envelope breakdown begins and is subsequently associated with polar microtubules of the mitotic spindle (Maldonado-Codina and Glover, 1992).

An abundant maternal supply of both cyclin A and B transcripts is present in the unfertilized Drosophila egg. Unlike the uniformly distributed cyclin A transcripts, those of cyclin B are concentrated at the posterior pole of egg. During embryogenesis cyclin B mRNA becomes incorporated into the progenitors of the germ-line, the pole-cells (Whitfield et al., 1989; Lehner and O'Farrell, 1990a; Raff et al., 1990). Cyclin B transcripts also become more closely concentrated around the somatic nuclei than those of cyclin $\mathrm{A}$ in a manner that requires the integrity of microtubules. In order to establish and maintain the posterior pole localisation, a component of the posterior cytoplasm is required. The distribution of cyclin $\mathrm{B}$ transcripts in a variety of mutant embryos that fail to form pole cells suggests that this localisation requires a polar granule associated component (Raff et al., 1990). In this paper we examine the distribution patterns of cyclin A and B transcripts during oogenesis and identify a signal in the cyclin B transcript required for both the posterior pole and nuclear localisation.

\section{Materials and methods}

\section{Northern hybridisation}

Hybridisation was to poly (A) ${ }^{+}$RNA immobilised on nitrocellulose filters (gift of Dr. K. O'Hare) with probes made by random oligo-labelling (Feinburg and Vogelstein, 1983) of cDNA fragments shown in Fig 2. Hybridisation was carried out at $42^{\circ} \mathrm{C}$ for 24 hours in $50 \%$ formamide, $0.75 \mathrm{M} \mathrm{NaCl}, 0.15 \mathrm{M}$ Tris- $\mathrm{HCl} \mathrm{pH}$ 8, $10 \mathrm{mM}$ EDTA, $200 \mu \mathrm{g} / \mathrm{ml}$ denatured salmon sperm DNA, $0.5 \%$ SDS, $36 \mathrm{mM} \mathrm{Na}_{2} \mathrm{HPO}_{4}, 4 \mathrm{mM} \mathrm{NaH} \mathrm{PO}_{4}, 5 \times$ Denhardts solution. Filters were washed in $5 \times$ Denhardts, $0.3 \mathrm{M} \mathrm{NaCl}, 60 \mathrm{mM}$ Tris$\mathrm{HCl} \mathrm{pH} 8,4 \mathrm{mM}$ EDTA, $2 \times 30$ minutes followed by $75 \mathrm{mM}$ $\mathrm{NaCl}, 15 \mathrm{mM}$ Tris-HCl, $1 \mathrm{mM}$ EDTA, $3 \times 10$ minutes. Filters were exposed for 7 days at $-70^{\circ} \mathrm{C}$ with intensifying screens.

\section{In situ hybridisation to whole mount embryos and ovaries}

In situ hybridisation was carried out according to the method of Tautz and Pfeifle (1989). Ovaries were dissected in $0.7 \% \mathrm{NaCl}$ and placed directly into fixative (4\% paraformaldehyde in PBS; phosphate buffered saline, $120 \mathrm{mM} \mathrm{NaCl}, 10 \mathrm{mM}$ sodium phosphate, with an equal volume of heptane). Embryos were also treated using this fixative after dechorionation in 50\% hypochlorite. Following fixation, embryos were devitellinised by vigorous shaking in 1:1 heptane:methanol (Mitchison and Sedat, 1983) and then pre-treated for hybridisation as described by Tautz and Pfeifle. Appropriate DNA fragments cloned into the vector $\mathrm{pKS}$ Bluescript (Stratagene) were used as templates to transcribe digoxigenin-labelled antisense RNA probes from either the T3 or T7 promoters for detection of the chimeric transcripts. Probes were also transcribed from $2.5 \mathrm{~kb}$ cyclin A and $2.7 \mathrm{~kb}$ cyclin B cDNA templates linearised with SalI and HindIII respectively, using the T7 promoter in the vector pNB40 (Brown and Kafatos, 1988) for detection of the endogenous cyclin $\mathrm{A}$ and $\mathrm{B}$ transcripts in ovaries. The cyclin B $3^{\prime}$ end probe was transcribed from the $2.7 \mathrm{~kb}$ cyclin B cDNA template linearised with EcoRV. Detection of hybridisation was by an alkaline phosphatase conjugated anti-digoxigenin antibody. Probe synthesis and detection were performed using BCL RNA labelling and nucleic acid detection kits. Prior to hybridisation, all probes were reduced in size by alkaline hydrolysis in $40 \mathrm{mM} \mathrm{NaHCO} 3,60 \mathrm{mM} \mathrm{Na} 2 \mathrm{CO}_{3}, \mathrm{pH} \mathrm{10,} \mathrm{for} 2$ hours at $60^{\circ} \mathrm{C}$. Probes were precipitated and resuspended in $50 \mu \mathrm{l}$ water. For each hybridisation $10 \mu \mathrm{l}$ of probe was added to embryos or ovaries in approx. $90 \mu$ l hybridisation solution. Hybridisations were carried out at $47^{\circ} \mathrm{C}$ for 16 hours. Hybridisation solution and subsequent treatments as Tautz and Pfeifle, 1989. All tissue was dehydrated through an ethanol series prior to mounting in $1.6 \mathrm{~g} / \mathrm{ml}$ Canada balsam in methyl salicylate. For visualisation of DNA embryos were stained for 20 minutes in $10 \mu \mathrm{g} / \mathrm{ml}$ Hoechst 33258 and mounted in $85 \%$ glycerol, $12.5 \%$ water, $2.5 \%$ propylgallate. Photography was carried out using a Nikon Microphot under bright field illumination.

\section{In situ hybridisation to sectioned ovaries}

Ovaries were dissected in $0.7 \% \mathrm{NaCl}$ and placed directly into fixative as above. After 2 hours fixation ovaries were dehydrated through an ethanol series and pre-treated for embedding and sectioning as described for embryos in Ingham et al., (1985). $15 \mu \mathrm{m}$ paraffin sections, cut using a Biocut microtome, were air dried and stored at $4{ }^{\circ} \mathrm{C}$ until use. Antisense RNA probes were prepared in the same way as for use in whole mount in situ hybridisation. Hybridisation conditions were as described in Ingham et al., 1985. Wash conditions were modified as follows: 4 washes for 20 minutes each in $1 \times$ salts, $50 \%$ formamide at $47^{\circ} \mathrm{C}$. 2 washes in NTE, $37^{\circ} \mathrm{C}, 30$ minutes each; 1 wash in NTE plus $20 \mu \mathrm{g} / \mathrm{ml}$ Ribonuclease A (Sigma), $37^{\circ} \mathrm{C}$ for 20 minutes (salts and NTE as in Ingham et al., 1985), 2 washes for 10 minutes in PBS followed by incubation with anti-digoxigenin antibody at 1 in 750 dilution in PBS for 1 hour. Excess antibody was removed by washing 4 times for 20 minutes each in PBS followed by 3 times 5 minute washes in $100 \mathrm{mM}$ Tris $\mathrm{pH} 9.5,100 \mathrm{mM} \mathrm{NaCl}, 50 \mathrm{mM} \mathrm{MgCl}_{2}$, $1 \mathrm{mM}$ levamisol (Sigma), 0.1\% Tween 20 (BDH). Detection of hybridisation carried out by adding $4.5 \mu \mathrm{l} \mathrm{NBT,} 3.5 \mu \mathrm{l}$ X-phosphate (BCL nucleic acid detection kit) to $1 \mathrm{ml}$ of above reaction buffer then placing a drop over sections and allowing colour reaction to develop for 30 to 40 minutes. Reactions were stopped by washing in PBS and allowing to air dry. Tissue was mounted in $85 \%$ glycerol, $12.5 \%$ water, $2.5 \%$ propylgallate and viewed with bright field illumination using a Nikon Microphot-FX.

\section{Transformation constructs}

All constructs were made using standard techniques and derived from the following genomic and cDNA clones, as shown in Fig. 3: pKScycA and pKScycB are $11 \mathrm{~kb}$ BamHI and 10kb SalI genomic fragments containing the complete cyclin A and B transcription units, cloned in the vector pKS Bluescript (Stratagene). The vector NotI and SalI sites on the $5^{\prime}$ and $3^{\prime}$ sides of the inserts were used for subcloning. $2.5 \mathrm{~kb}$ cyclin $\mathrm{A}$ and $2.7 \mathrm{~kb}$ cyclin $\mathrm{B}$ cDNA clones in the vector pNB40 (Brown and Kafatos, 1988) and $2.3 \mathrm{~kb}$ cyclin B cDNA described below and subcloned as an EcoRI fragment in pKS Bluescript.

Construct ABB-1 consists of the following fragments: $4.6 \mathrm{~kb}$ NotI-NcoI genomic fragment including the promoter plus $5^{\prime}$ untranslated region of cyclin A; $1.7 \mathrm{~kb} N c o \mathrm{I}-E c o R V$ cyclin B cDNA coding region fragment and $1.2 \mathrm{~kb}$ genomic EcoRV-KpnI 
fragment containing the $3^{\prime}$ untranslated of cyclin B plus approximately 400 nucleotides of non-transcribed sequence.

The AZB-1 construct utilises the same fragments containing the promoter plus $5^{\prime}$ untranslated sequences of cyclin $\mathrm{A}$ and $3^{\prime}$ untranslated of cyclin B. The coding region of cyclin B is replaced by that of the E. coli $\beta$-galactosidase gene from the vector pMC 1871 (Pharmacia, Casadaban et al., 1983) by insertion of an NcoI linker into the unique $S m a I$ site of the vector allowing excision of the $3.0 \mathrm{~kb} \beta$-galactosidase coding region fragment by digestion with SalI, end-filling with T4 DNA polymerase and digestion with NcoI. BZB-1 construct made as above but using a $4.0 \mathrm{~kb} \mathrm{NcoI}$ fragment including the promoter plus $5^{\prime}$ untranslated of cyclin B inserted into the NcoI site introduced into pMC1871. AZB-2 construct made as AZB-I, but using a 200bp DraI-EcoRI cDNA fragment containing the $3^{\prime}$ untranslated of the smaller cyclin B transcript.

All constructs were finally subcloned into the P-element transformation vector pW8 (Klemenz et al., 1987) and co-injected into $w^{1118}$ embryos at $500 \mu \mathrm{g} / \mathrm{ml}$ with the helper plasmid $\Delta 2-3$ at 200 $\mu \mathrm{g} / \mathrm{ml}$ (Laski et al., 1986) in injection buffer $\left(0.1 \mathrm{mM} \mathrm{NaPO}_{4}, 5\right.$ $\mathrm{mM} \mathrm{KCl}$ ). Transformants were identified by their wild-type eye colour phenotype and single insert homozygous lines made by standard methods. For each of the ABB-1, AZB-1 and AZB-2 constructs single transformed line were examined, for $\mathrm{BZB}-1$ two independent lines were examined.

\section{Cloning and sequencing of the $2.3 \mathrm{~kb}$ cyclin $B$ cDNA}

The cDNA was cloned from a library made from testes poly $(\mathrm{A})^{+}$ RNA (gift of T. Hazelrigg) in the vector $\lambda$ ZAP II. Positive clones were detected by hybridisation to an oligo-labelled probe made from the $1.6 \mathrm{~kb} E c o \mathrm{RI}-E c o \mathrm{RV}$ cyclin B coding region fragment shown in Figure 2. A DraI-EcoRI fragment containing the $3^{\prime}$ end of the cDNA was subcloned into the vector pKS Bluescript and sequenced using a Sequenase kit (United States Biochemical).

\section{Polymerase Chain Reaction amplification of RNA}

Total RNA was prepared from approximately fifty pairs of hand dissected ovaries. These were homogenised in $100 \mu$ l of lysis buffer ( $8 \mathrm{M}$ urea, $0.35 \mathrm{M} \mathrm{NaCl}, 10 \mathrm{mM}$ Tris $\mathrm{pH} 7.5,10 \mathrm{mM}$ EDTA) and extracted 3 times with 9:1 phenol:chloroform saturated with lysis buffer and once with chloroform. RNA was precipitated using 2 volumes ethanol, 0.1 volume $3 \mathrm{M}$ sodium acetate $\mathrm{pH} 5.5$ at $-70^{\circ} \mathrm{C}$ for 1 hour, washed in $70 \%$ ethanol and resuspended in $50 \mu \mathrm{l}$ water. $5 \mu \mathrm{l}$ of RNA was used as template for first strand cDNA synthesis followed by PCR amplification (Kawasaki, 1990). The region between nucleotides 1840 and 2463 in the sequence of Whitfield et al. (1990) was amplified and the two PCR products corresponding to the $3^{\prime}$ untranslated regions of each cyclin B transcript were subcloned into the vector pKS Bluescript and sequenced using a Sequenase kit (United States Biochemical).

\section{Results}

Germ-line transcription of the Drosophila cyclin genes

Previous studies suggested that the accumulation of cyclin $\mathrm{B}$ mRNA at the posterior pole of the egg must occur during oogenesis, since it is already concentrated in this region prior to fertilisation (Raff et al., 1990). In order that we might study the stage during oogenesis at which this concentration occurs we first undertook to examine cyclin A and $B$ transcripts present in the ovaries of adult female flies (Fig. 1). A probe derived from a full-length cyclin A cDNA, detects a single ovary-specific transcript of $2.5 \mathrm{~kb}$ (Fig. 1A, lane 4) corresponding to the size of a cyclin A mRNA detected previously in early embryos (Whitfield et al., 1989). A fragment derived from the coding region of a fulllength $(2.7 \mathrm{~kb})$ cyclin B cDNA, detects two ovary-specific transcripts in adult female flies of $2.7 \mathrm{~kb}$ and $2.3 \mathrm{~kb}$ (Fig. $1 \mathrm{~B}$, lane 4$)$. The $2.7 \mathrm{~kb}$ transcript is female specific and corresponds to the major maternally provided RNA detected previously in 0 to 2 hour embryos, prior to the onset of zygotic transcription (Lehner and O'Farrell, 1990b; Whitfield et al., 1989). A $2.3 \mathrm{~kb}$ transcript, previously thought to be male specific (Whitfield et al., 1989) is present in both adult males and females (Fig. 1B, lanes 3 and 4).

We find greatly reduced levels of each of these transcripts in the poly $(\mathrm{A})^{+}$RNA of adult males and females that are the progeny of a P-M dysgenic cross (Fig. 1, lanes 1 and 2 respectively on each filter). As these flies essentially lack testes and ovaries, respectively, we conclude that the majority of transcription of both cyclin A and cyclin B is germline specific in the adult. The continuing low levels of transcription detected may be due to incomplete penetrance of the dysgenic effect. In order to distinguish the forms of cyclin B transcript, we hybridised a northern blot filter with a cDNA fragment derived from the $3^{\prime}$ end of the $2.7 \mathrm{~kb}$ cDNA (the cDNA fragments used to make probes are shown in Fig. 2). This probe detects only the larger transcript present in females (Fig. 1C, lane 4). Hence we conclude that the shorter transcripts present in both males and females are missing sequences present in the 3' untranslated region of the longer transcripts.

We wished to isolate a shorter cyclin B cDNA from the longer cDNAs previously sequenced (Lehner and O'Farrell, 1990b; Whitfield et al., 1990). We therefore screened a cDNA library prepared from adult testes poly $(\mathrm{A})^{+}$RNA (see Materials and methods) using a probe prepared from the coding region of the $2.7 \mathrm{~kb}$ cyclin B cDNA (see Fig. 2). The sequence (Fig. 2B) indicates that smaller transcripts can be generated by a splicing mechanism which must remove 393 nucleotides from the central region of the 776 nucleotide $3^{\prime}$ untranslated of the larger $2.7 \mathrm{~kb}$ transcript. The splice donor and acceptor sites are in accordance with consensus sequences determined by Mount (1982), and Burtis and Baker (1989), except for the presence of an adenine residue a position normally occupied by a pyrimidine (see Fig. 2). The two transcripts may also utilise differing lengths of poly $(\mathrm{A})^{+}$tail to fully account for the size differences observed.

We wished also to determine whether the smaller cyclin $\mathrm{B}$ transcripts present in adult female flies are generated in the same way. We therefore sequenced polymerase chain reaction (PCR) amplified segments from the $3^{\prime}$ untranslated regions of the two cyclin $\mathrm{B}$ transcripts detected in adult females, using total RNA prepared from ovaries as template for first strand cDNA synthesis (see Materials and methods). The smaller transcript present in adult females was also found to be generated by the removal of 393 nucleotides from its $3^{\prime}$ untranslated region.

\section{Identification of a posterior pole localisation sequence in cyclin $B$ mRNA}

In order to define the sequences responsible for the posterior pole localisation of cyclin B transcripts, we con- 


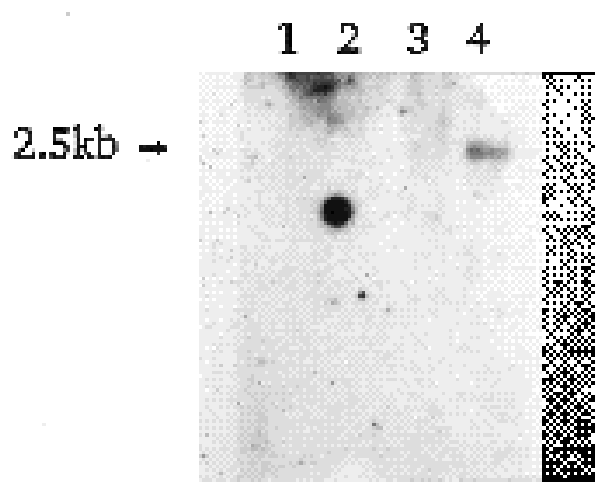

A

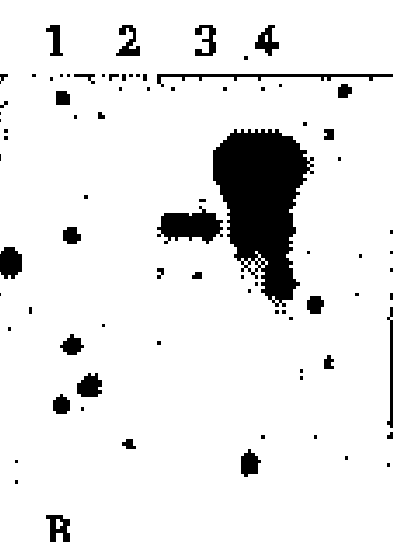

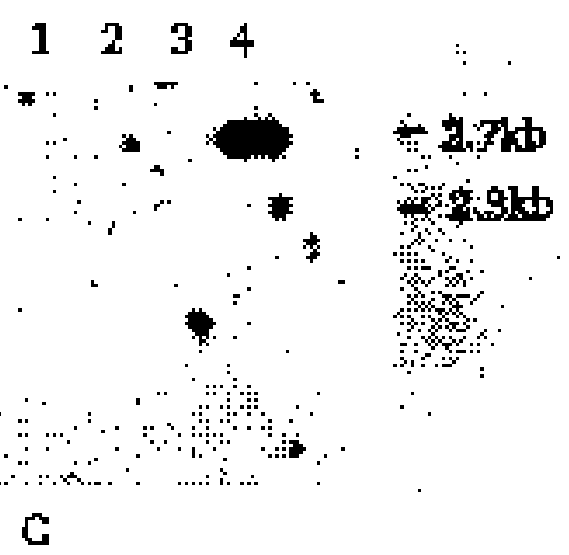

Fig. 1. Northern hybridisation showing transcripts detected in adult flies by cyclin A and B cDNA probes. Three identical northern blot filters were hybridised with probes made from (A) a $1.8 \mathrm{~kb}$ SalI-Not I fragment derived from a $2.5 \mathrm{~kb}$ cyclin A cDNA, (B) the coding region (1.35kb EcoRV-EcoRI fragment) and (C) the 3' untranslated (0.7kb EcoRV-NotI fragment) of the $2.7 \mathrm{~kb}$ cyclin B cDNA shown in Figure 2A. On each filter, lane 1 contains poly(A) ${ }^{+}$RNA from dysgenic males; lane 2, dysgenic females; lane 3, wild-type (Oregon R) males; and lane 4, Oregon $\mathrm{R}$ females. Transcript sizes in kilobases $(\mathrm{kb})$ are indicated.

structed chimeric genes containing fragments of the cyclin $\mathrm{A}$ and $\mathrm{B}$ genes and the E. coli lac $Z$ gene, referred to below as $\mathrm{A}, \mathrm{B}$ and $\mathrm{Z}$ respectively. (see Fig. 3). We further distinguish the origins of the $3^{\prime}$ cyclin B sequences as to whether they originate from genomic DNA, B-1, or the shorter cDNA, B-2. Hence we adopt a nomenclature in which a construct having the promoter plus $5^{\prime}$ untranslated sequence of cyclin $\mathrm{A}$, the coding region of the lac $Z$ gene and a genomic fragment containing the $3^{\prime}$ untranslated sequence of the cyclin B gene is referred to as AZB-1. We used P-element mediated germ line transformation to generate transformed lines carrying these constructs. The distribution patterns of the chimeric RNAs expressed from these genes in transformed embryos were then examined by the whole-mount in situ hybridisation technique of Tautz and Pfeifle (1989; see Materials and methods) using antisense RNA probes corresponding to appropriate fragments from each construct underlined in Fig. 3.

The distribution of AZB-1 transcripts detected using a probe corresponding to the coding region of the lac $Z$ gene
A

$2.3 \mathrm{~kb} \mathrm{cyclin} B$ CDNA:
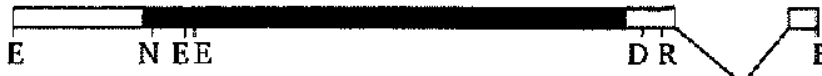

$2.7 \mathrm{~kb}$ cyclin B cDNA:

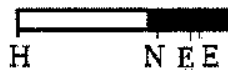

D R

Probes

coding:

3' untranslated:

B

Donot:

Acceptor.

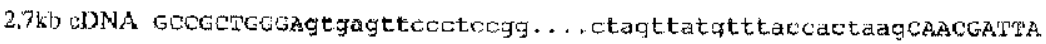

Consencis

GTRAGT

XYYXYYYYYYNAYAG
Fig. 2. (A) Structures of longer and shorter forms of cyclin B cDNAs. A $2.3 \mathrm{~kb}$ transcript is generated by the removal of a 393 nucleotide (nt) region from the $3^{\prime}$ untranslated region of the $2.7 \mathrm{~kb}$ transcript. Underlined below the $2.7 \mathrm{~kb}$ cDNA are the fragments used as probes to distinguish the two transcripts. Black and white boxes indicate coding and untranslated sequences respectively. $\mathrm{D}=$ Dra $\mathrm{I}, \mathrm{E}=$ EcoRI, $\mathrm{H}=$ HindIII, $\mathrm{N}=$ NcoI, $\mathrm{Nt}=$ Not $\mathrm{I}, \mathrm{R}=E c o \mathrm{RV}$. (B) Relevant regions of the sequences of $2.3 \mathrm{~kb}$ and $2.7 \mathrm{~kb}$ cyclin B cDNAs. Splice donor and acceptor sequences in the $2.7 \mathrm{~kb}$ cDNA are boxed. Sequences removed by splicing are shown in lower case letters and correspond to nucleotides 2004 to 2397 in the sequence of Whitfield et al. (1990). The non-consensus A residue in the splice acceptor sequence is underlined. Consensus donor and acceptor sequences (Mount, 1982) are shown below the corresponding regions of the $2.7 \mathrm{~kb}$ cDNA. In the consensus acceptor sequence the length and composition of the pyrimidine rich tract is variable. The arrow indicates the splice junction in the $2.3 \mathrm{~kb}$ cDNA. $\mathrm{N}=\mathrm{A}, \mathrm{C}, \mathrm{G}$ or T. $R=$ Purine, $Y=$ Pyrimidine. 
A

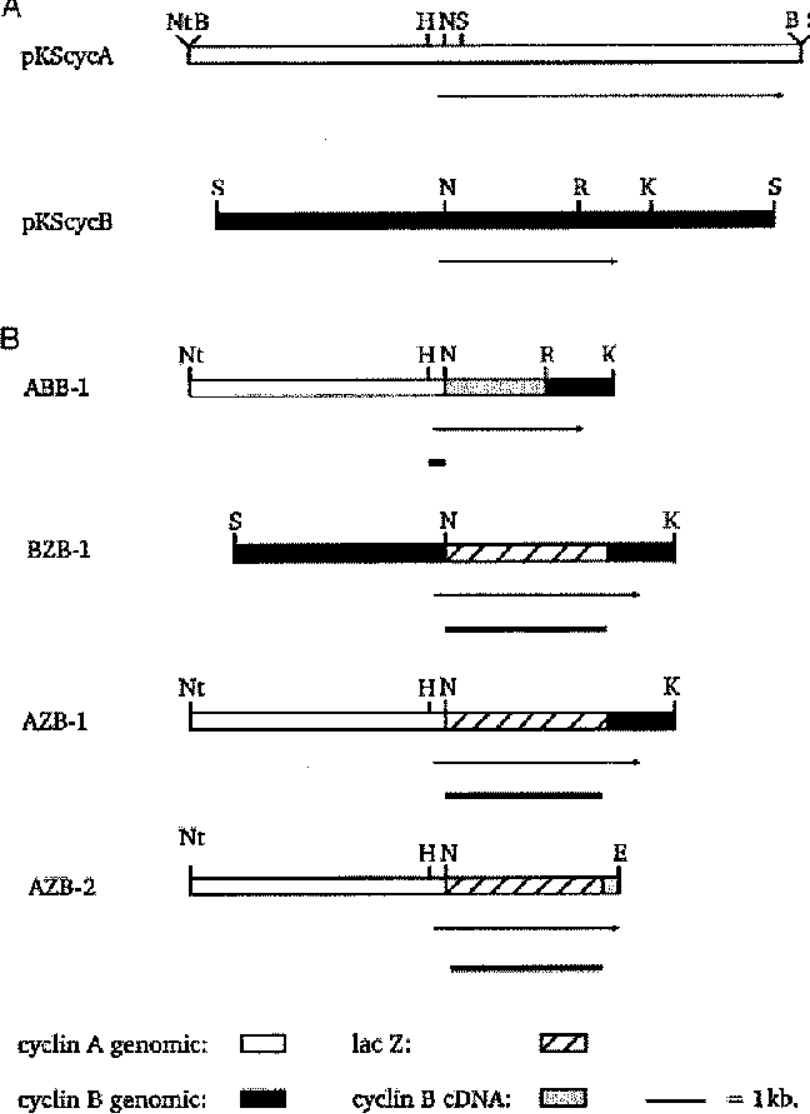

Fig. 3. (A) Genomic fragments containing the cyclin A and B genes. pKScycA and pKScycB are $11 \mathrm{~kb}$ BamHI and 10kb SalI fragments including the complete cyclin A and B transcription units and the necessary promoter elements to direct transcription in oogenesis. (B) Chimeric cyclin gene constructs used to identify the localisation signal in the $2.7 \mathrm{~kb}$ cyclin $\mathrm{B}$ transcript composed of cyclin A or B genomic DNA, the E. coli lacZ gene or cyclin B cDNA fragments as indicated in the key. A $3^{\prime}$ segment derived from the cyclin B genomic sequence is referred to as B-1, whereas the 3' segment derived from the shorter cyclin B cDNA is referred to as B-2 (see text for details). Arrows indicate the transcribed regions of the cyclin $\mathrm{A}$ and $\mathrm{B}$ genomic fragments and of the chimeric genes. All constructs are aligned at their transcriptional start sites. DNA fragments used to make probes are indicated below each construct. These fragments were subcloned into $\mathrm{pKS}$ Bluescript and used to transcribe digoxgenin labelled antisense RNA probes. $\mathrm{B}=$ Bam $\mathrm{HI}, \mathrm{E}=E c o \mathrm{RI}, \mathrm{H}=$ HindIII, $\mathrm{K}=K p n \mathrm{I}$, $\mathrm{N}=$ NcoI, $\mathrm{Nt}=\operatorname{Not} \mathrm{I}, \mathrm{R}=E c o \mathrm{RV}, \mathrm{S}=$ SalI .

is shown in Fig. 4. Initially the message appears evenly distributed throughout the unfertilised egg (Fig. 4A), except for a concentrated cap at the posterior pole. The message in the body of the syncytial embryo becomes redistributed around the somatic nuclei as they migrate to the cortex in nuclear cycles 7-8 (Fig. 4B). The AZB-1 transcripts appear to be closely associated with the migrating nuclei in the manner of the endogenous cyclin B transcript rather than being simply excluded from the expanding yolk mass as observed for endogenous cyclin A transcripts (Raff et al., 1990). The message concentrated at the posterior pole becomes incorporated into the pole buds whose formation is initiated in early cycle 9 as nuclei arrive at the posterior cortex. Following cellularisation, the bulk of AZB-1 transcripts are cleared from the embryo except for those in the pole cells (Fig. 4C) which remain detectable during germ band extension (Fig. 4D). Transcripts of the chimeric ABB1 (not shown) and BZB-1 (Fig. 5D) genes have essentially identical distributions to those of the AZB-1 gene. They become incorporated into pole cells in nuclear cycles 8 to 9 where they are distributed on either side of the nuclei (Fig. 5, D, E, arrow indicates regions where RNA is most concentrated). They also show the peri-nuclear association typical of endogenous cyclin B RNA (Fig. 5, D, F). The only intact part of the cyclin $\mathrm{B}$ message retained in all of these chimeric genes corresponds to the $3^{\prime}$ untranslated region. This suggests that it is these sequences that direct cyclin B RNA in its characteristic pattern.

We have confirmed this by examining the distribution of transcripts from a chimeric gene in which the shorter spliced form of the $3^{\prime}$ untranslated region, derived from the $2.3 \mathrm{~kb}$ cyclin B cDNA, replaces the genomic 3' end fragment used in the AZB-1 construct (Fig. 3, construct AZB2). Transcripts of the AZB-2 gene are not concentrated at the posterior pole either in unfertilised eggs (not shown) or in the syncytial embryo (Fig. 5, A, B, arrow indicate pole buds). These transcripts also fail to show the peri-nuclear association, (Fig. 5, A, C) shown by the endogenous cyclin B message (Raff et al., 1990) in syncytial embryos. Instead the AZB-2 transcripts appear evenly distributed in the body of the syncytial embryo. Thus the deletion of part of the $3^{\prime}$ untranslated sequence of the larger transcript must disrupt the sequences required for both posterior pole and perinuclear localisation.

\section{Distributions of cyclin A and B transcripts in oogenesis}

We have compared the patterns of the Drosophila cyclin A and B transcripts during oogenesis by in situ hybridisation using the coding regions of the genes as probes. Both genes are transcribed in the germarium (g; Fig. 6A, B). Here, in the anterior region, stem cells undergo mitosis to generate a daughter stem cell and a cystoblast which then undergoes four further mitotic divisions giving the sixteen precursor cells of the stage 1 follicle (reviewed by Mahowald and Kambysellis, 1980). These cells differentiate, without further division, into fifteen nurse cells which undergo rounds of polyploidisation during stages 2 to 10 of oogenesis and the oocyte itself. Cyclin B transcripts unlike those of cyclin A, are clearly present at higher levels, in the presumptive oocyte, where they remain concentrated until stage 7 (Fig. $6 \mathrm{~B}$, arrowed in stage 7 follicle). Subsequently these transcripts appear to become dispersed in the cytoplasm of the oocyte as its volume increases (Fig. 6B, stage 8 follicle). The transcription of both genes then resumes in the nurse cells from stages 9 and 10 prior to the deposition of their contents into the oocyte at stage 12 . Whole-mount in situ hybridisation shows that there is no suggestion of transcript accumulation at the posterior pole at this time (Fig. 6B, stage 10 follicle). We confirmed that cyclin B transcripts were present only in the nurse cells and not the oocytes of stage 10 follicles by in situ hybridisation to sectioned tissue (not shown). Transcripts enter the oocyte from the nurse cell complex at stages 12 to 13 (Fig. 7A) and become con- 

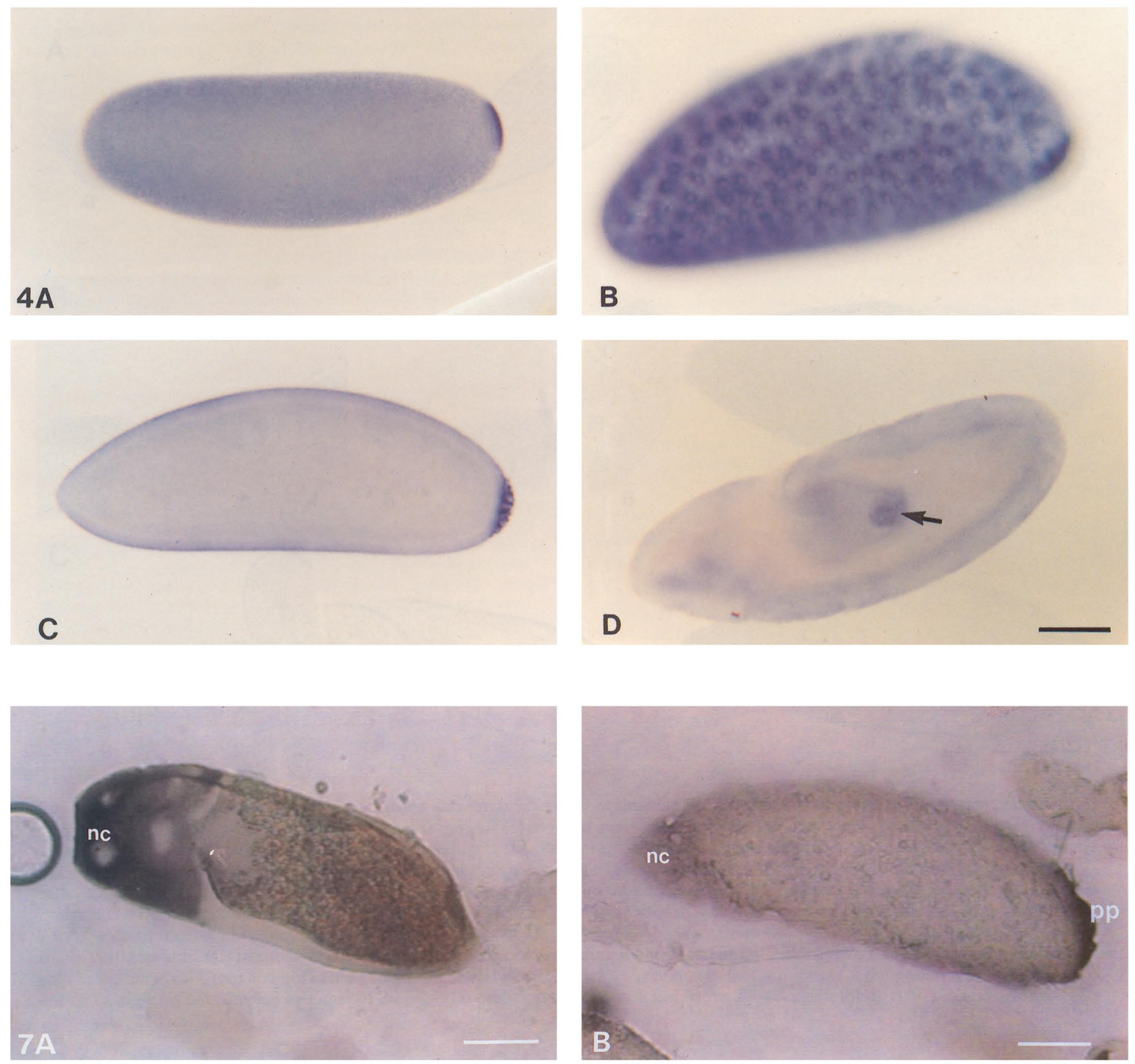

Fig. 4. Distribution of the chimeric AZB-1 RNA. In situ hybridisation to whole embryos with a digoxgenin-labelled antisense RNA probe corresponding to the lac $Z$ coding region fragment. (A) unfertilised egg; (B) syncytial embryo at cycle 10 with transcripts concentrated around nuclei at surface of embryo. (C) newly cellularised cycle-14 embryo with RNA concentrated in pole cells to right; (D) germ band extended embryo with AZB-1 RNA present in pole cells, indicated by arrow. All embryos have anterior to left and posterior to right. Bar is $100 \mu \mathrm{m}$.

Fig. 7. In situ hybridisation to sections through late stage follicles using an anti-sense RNA probe showing entry of cyclin B transcripts from the nurse cells (nc) into the oocyte at stages 12-13 (A). By stage 14 cyclin B transcripts have dispersed throughout the oocyte and are concentrated at the posterior pole (B, pp). Bar is $100 \mu \mathrm{m}$. 


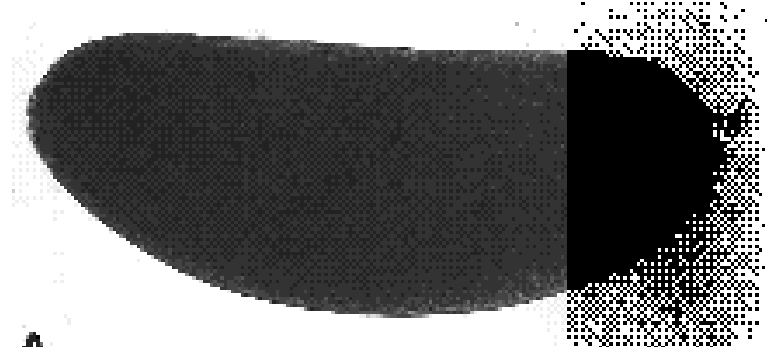

\section{A -}

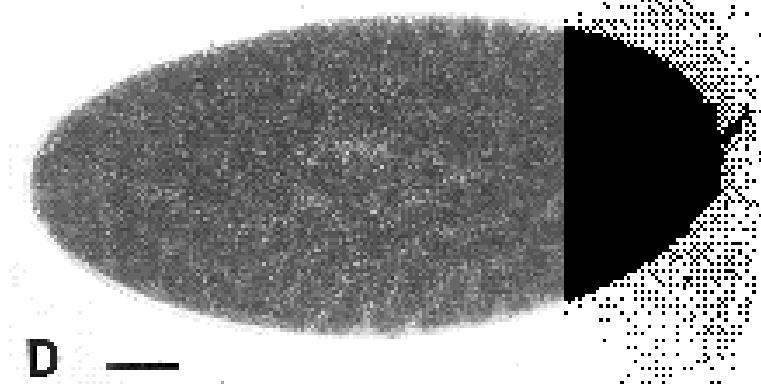

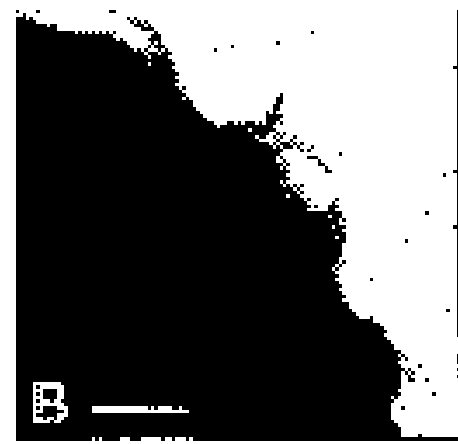
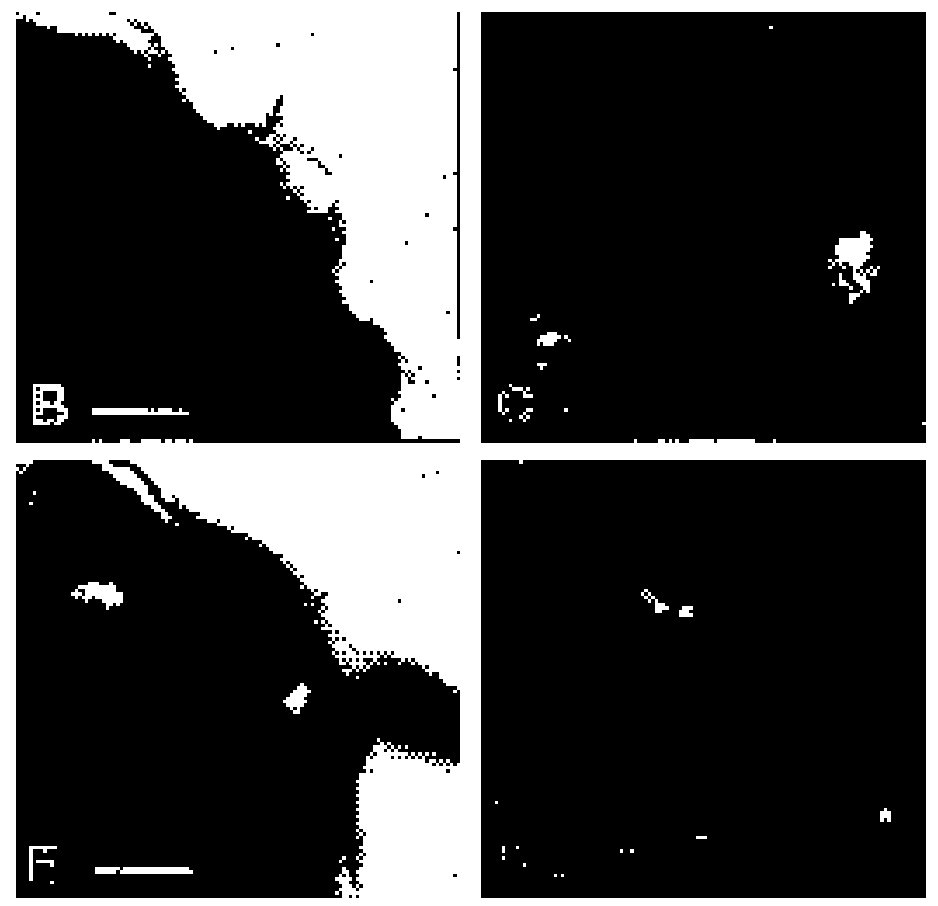

Fig. 5. In situ hybridisation to whole embryos showing the distributions of the chimeric AZB-2 (A-C) and BZB-1 (D-F) transcripts, detected using a lac $Z$ coding region probe. The AZB-2 transcripts appear evenly distributed throughout the body of a cycle-10 embryo (A). They are not detected in the pole buds (C). The arrows indicate those regions of pole buds in which cyclin B transcripts are normally concentrated. The AZB-2 RNA also fails to show perinuclear association (C; $n$ indicates nuclei). The BZB-1 transcripts are both concentrated at the posterior pole (D,E; arrows indicate regions where RNA is most concentrated) and show peri-nuclear association $(\mathrm{F})$. DNA is visualised in B, C, E and F with staining with Hoechst 33258, dark staining indicates RNA. Bars in A and D are $100 \mu \mathrm{m}$, in B, C, $\mathrm{E}$ and $\mathrm{F}, 10 \mu \mathrm{m}$.

centrated at the posterior pole during stages 13 to 14 (Fig. 7B).

We wished to determine whether the two forms of the cyclin B transcript showed any differential distribution during oogenesis. We therefore examined the in situ hybridisation pattern given by a probe made from the $3^{\prime}$ untranslated sequence of the $2.7 \mathrm{~kb}$ cyclin $\mathrm{B}$ cDNA, with that of a probe made from the cyclin $\mathrm{B}$ coding region (see Fig. 2A for details of the probe used) in order to detect only the larger cyclin B RNAs. We were able to detect transcripts only in the nurse cell complex from stages 9 to 10 onwards and not in the posterior germarium (g; Fig. 6C) or early stage oocytes. This contrasts with the ability of the coding region probe to detect both patterns of cyclin B transcript distribution (Fig. 6B). Hence it appears that the smaller form of the cyclin B message is preferentially synthesised in the early stages of oogenesis. Restricted synthesis of the larger message in the nurse cell complex (Fig. $6 \mathrm{~B}, \mathrm{C})$ is consistent with the previous finding that this is the only maternal cyclin B transcript that can be detected in 0 to 2 hour embryos by Northern blotting (Whitfield et al., 1989). The cyclin B RNA that is present at the posterior pole appears therefore to be both synthesised and localised late in oogenesis and thus follows a distinct pattern of expression from that seen in the earlier stages. We are unable to detect intermediate stages of cyclin B mRNA accumulation during oogenesis suggesting that structures able to specifically recognise and capture this message might already be positioned at the posterior pole.

\section{Discussion}

We have compared the distributions of the Drosophila cyclin A and B transcripts in oogenesis and find both to be present in the cells of the germarium, consistent with a requirement for cyclins in that region of the ovariole, in which mitosis takes place. In subsequent stages of oogenesis the pattern of accumulation and redistribution of cyclin B transcripts is more complex than that of cyclin A. Only cyclin B transcripts are seen in the presumptive oocyte in the early stages of oogenesis. These are the shorter forms of the cyclin B RNA that lack a segment of the 3' untranslated sequence present in the transcripts produced at later stages. These transcripts persist in the oocyte until stages 7 to 8 . From stages 9 to 10 onwards both cyclin A transcripts and a larger form of the cyclin B transcript accumulate in the nurse cells prior to the deposition of their contents into the oocyte in stages 11 to 12 of oogenesis. Cyclin B transcripts are then accumulated at the posterior pole in stages 13 and 14. This is consistent with previous findings that cyclin B transcript accumulation is disrupted in eggs of females homozygous for the mutations cappuccino, spire, staufen and oskar (Manseau and Schupbach, 1989; Schup- 

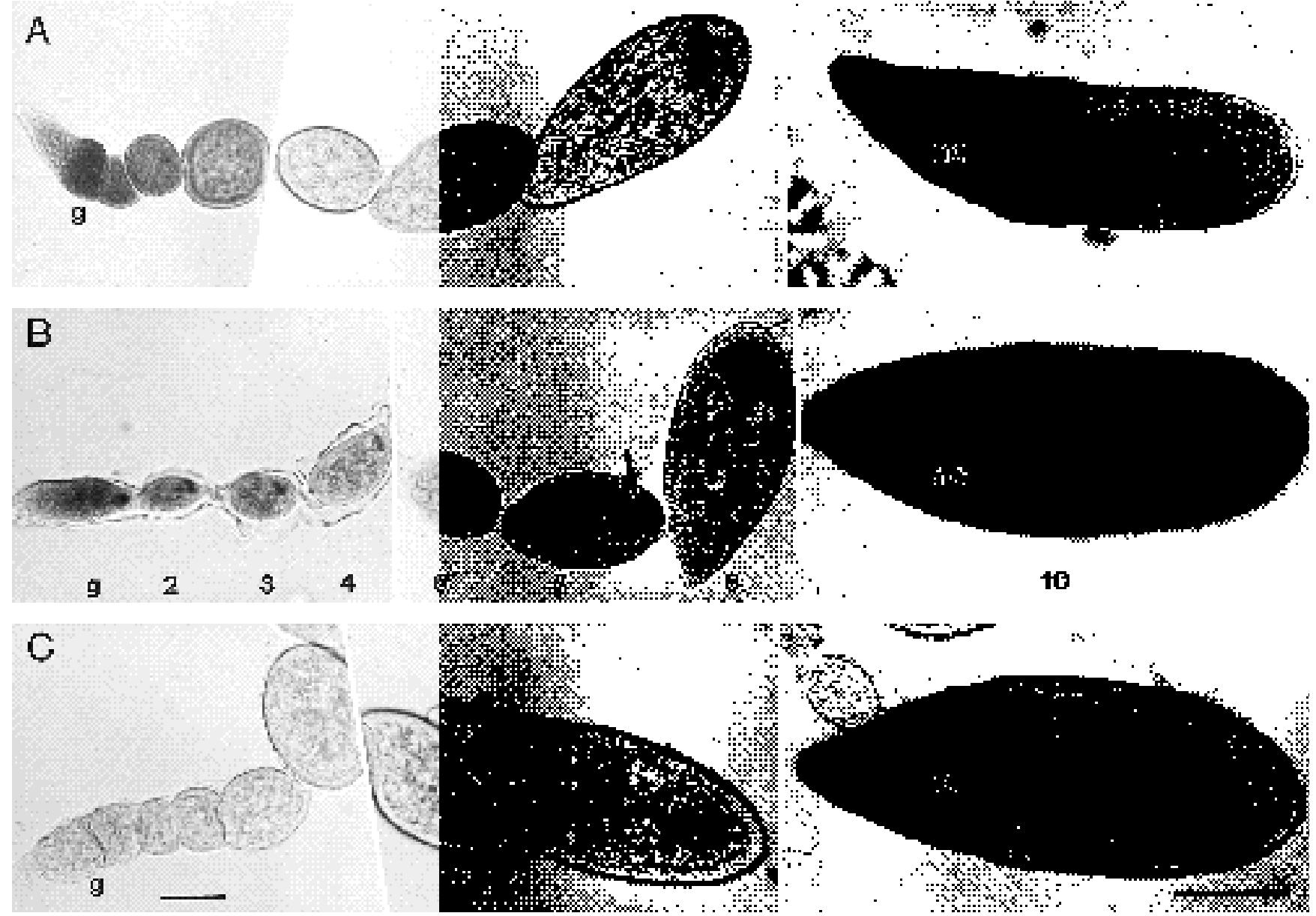

Fig. 6. In situ hybridisation to whole ovaries using anti-sense RNA probes showing the distributions of cyclin A and B transcripts during oogenesis (see Materials and methods). Stages of oogenesis (Mahowald and Kambysellis, 1980) are indicated below the follicles shown in panel B. (A) Hybridisation with a probe corresponding to the coding region and $3^{\prime}$ untranslated sequences of the cyclin A cDNA shows transcripts present in the posterior germarium $(\mathrm{g})$ but not in subsequent stages of oogenesis, until the onset of transcription in the nurse cells (nc) at stages 9-10. (B) Hybridisation with a probe corresponding to the coding region and $3^{\prime}$ untranslated sequences of the $2.7 \mathrm{~kb}$ cyclin B cDNA detects transcripts in the germarium (g) which continue to be seen in the presumptive oocyte (indicated by arrow in stage7 follicle) until stage 8 when they appear to disperse in the oocyte cytoplasm. Abundant transcripts are detected in the nurse cells (nc) in stages 9-10 onwards. (C) In situ hybridisation using a probe corresponding to the $3^{\prime}$ end of the $2.7 \mathrm{~kb}$ cyclin B cDNA detects transcripts only in the nurse cells (nc) and not in the germarium or early stage follicles. Accumulation of transcripts at the posterior pole of the oocyte (to right) is not detected by either of the cyclin B probes at these stages. Bar below early stage follicles is $50 \mu \mathrm{m}$ and below stage10 follicles, $200 \mu \mathrm{m}$.

bach and Wieschaus, 1986; Lehmann and Nusslein-Volhard, 1986). These mutations also disrupt the accumulation of vasa protein at the posterior pole which normally occurs at stage 10a of oogenesis (Hay et al., 1988; Lasko and Ashburner, 1990). This suggests that the accumuation of cyclin B transcripts may be dependent upon their interaction with components of the polar granules already positioned at the posterior pole.

We have shown that the complete $3^{\prime}$ untranslated sequences of the larger form of the cyclin B transcript direct them to the posterior pole during oogenesis. Two other maternally provided RNAs in which localisation signals have been identified are those encoding the anterior morphogen bicoid (Macdonald and Struhl, 1988), and the dorso-ventral determinant K10 (Cheung et al., 1992). bicoid RNA is concentrated at the anterior pole of unfertilised eggs and its accumulation has been shown to occur in several phases during stages 6 to 12 of oogenesis (St.Johnston et al., 1989). K10 transcripts however appear to be selectively transported into the oocycte from as early as stage 2 of oogenesis and they accumuate at its anterior margin (Cheung et al., 1992). Both the initial localisation patterns and the structures involved appear therefore to be distinct for each of these RNAs. All however are dependent on sequences present in the $3^{\prime}$ untranslated of the transcript. Examination of the $3^{\prime}$ untranslated regions of both the bicoid and K10 transcripts reveal a number of long inverted repeats predicting that these regions are capable of forming extensive secondary structures. The significance of this in directing the localisation of these transcripts is uncertain but similar examination of the sequence of cyclin B transcripts predicts that it is incapable of forming such struc- 
tures. Primary sequence may therefore be of greater importance in directing the localisation of this RNA.

In addition to being concentrated at the posterior pole, cyclin B transcripts in the body of the embryo become associated with the nuclei as embryonic development proceeds. As this association is disrupted by microtubule destabilising drugs, it has been suggested that either nascent cyclin $\mathrm{B}$ polypeptides on polysomes might be associating with microtubules and dragging the RNA with them, or that the cyclin B RNA itself is targeted to microtubules (Raff et al., 1990). Our finding in this paper support the latter explanation, since the 393 nucleotide $3^{\prime}$ untranslated sequence of the larger maternal cyclin B transcript required for posterior accumulation of the mRNA is also required for its perinuclear localisation in the body of the syncytial embryo. It is possible that either discrete sequence elements within the $3^{\prime}$ untranslated region are responsible for the two patterns of localisation or that the same sequence is targeting the RNA in both processes. This can only be resolved by further dissecting the region using the type of experimental approach we have described.

Although it was previously postulated that two distinct mechanisms are responsible for the two patterns of localisation observed, the two processes may share a common intermediary. Such a molecule could be associated with the astral microtubules nucleated by centrosomes. This is possible since the polar granules are also observed to cluster around centrioles in a number of Drosophila species (Rabinowitz, 1941; Counce, 1963; Mahowald, 1968). Furthermore, pole cell formation itself appears to be triggered by an interaction between a pole plasm component and centrosomes, or a molecule associated with the centrosomes (Raff and Glover, 1989). There is currently no indication of which polar granule component could interact with centrosomal microtubules and so it must remain a matter of speculation as to whether this component could also be present associated with astral microtubules in the body of the embryo. It is feasible that such a molecule could form part of a cytoskeletal network required for the transport of posterior pole components from the nurse cells. The mechanism of this transport is not well understood but it has been suggested that the products of the capu and spir genes, needed for both anterior-posterior and dorsal-ventral patterning, may contribute to such a network required to localise morphogens (Manseau and Schupbach, 1989).

The functional purpose of targeting cyclin B transcripts to either the peri-nuclear regions of the syncytial embryo or the posterior pole of the developing oocyte remains uncertain. A possible explanation for the former pattern of localisation could be to help direct cyclin B protein to its site of action, prior to it becoming complexed with p34cdc2. We presume that the cyclin B transcripts at the posterior pole of the embryo will be translated later during the development of the germ line. They persist in the pole cells throughout germ band extension (Whitfield et al., 1989), but there appears to be no increase in the level of cyclin B protein detectable by immunofluorescence in pole cells, above that of the surrounding cells, at least until cycle 15 (G. Maldonado-Codina, personnal communication). Furthermore when cyclin B transcripts are detected in the oocyte during stages 2 to 7 of oogenesis, cyclin B protein is undetectable in this cell by immunofluorescence (B.D. unpublished observation) although it is present in the unfertilised egg (Whitfield et al., 1990). Hence translational repression of cyclin B may be functioning both in oogenesis and later in embryogenesis. Detailed examination of the fate of cyclin B mRNA in the pole cells and the developmental regulation of its translation should assist in elucidating the possible role of cyclin B in the proliferation of these cells.

We thank Tulle Hazelrigg for the gift of the adult testes cDNA library and Kevin O'Hare for the kind loan of the northern blot filters. We also thank Gabbie Maldonado-Codina for communicating unpublished data, Charles Girdham and Jordan Raff for comments and criticisms. This work was supported by the Cancer Research Campaign and a SERC studentship to B.D.

\section{References}

Beach, D., Durkacz, B. and Nurse, P. (1982). Functionally homologous cell cycle control genes in budding and fission yeast. Nature 300, 706709.

Brown, N. H. and Kafatos, F. (1988). Functional cDNA libraries from Drosophila embryos. J. Mol. Biol. 203, 425-437.

Burtis, K. C. and Baker, B. S. (1989). Drosophila doublesex gene controls somatic sexual differentiation by producing alternately spliced mRNAs encoding related sex-specific polypeptides. Cell 56, 997-1010.

Casadaban, M. J., Martinez-Arias, A., Shapira, S. K., and Chou, J. (1983). $\beta$-galactosidase gene fusions for analysing gene expression in E.coli and yeast. Methods in Enzymol. 100, 293-308.

Cheung, H. K., Serano, T. L., and Cohen, R. S. (1992). Evidence for a highly selective RNA transport system and its role in establishing the dorsoventral axis of the Drosophila egg. Development 114, 653-661.

Counce, S. J. (1963). Developmental morphology of polar granules in Drosophila including observations on pole cell behaviour during embryogenesis. J.Morph. 112, 129-145.

Draetta, G., Luca, F., Westendorf, J., Brizula, L., Rudermann, J. V. and Beach, D. (1989). $c d c 2$ protein kinase is complexed with both cyclin A and B: Evidence for proteolytic inactivation of MPF. Cell 56, 829-838.

Evans, T. E., Rosenthal, E. T., Youngbloom, J., Distal, D. and Hunt, T. (1983). Cyclin: a protein specified by maternal mRNA in sea urchin eggs that is destroyed at each cell division. Cell 33, 389-396.

Feinburg, A. P. and Vogelstein, B. (1983). A technique for labelling restriction endonuclease fragments to high specific activity. Analyt. Biochem. 132, 6-13.

Gautier, J. and Maller, J. L. (1991). Cyclin B2 and pre-MPF activation in Xenopus oocytes. EMBO J. 10, 177-182.

Hay, B., Ackerman L., Barbel, S., Jan, L. Y. and Jan, Y. N. (1988). Identification of a component of Drosophila polar granules. Development 103, 625-640.

Ingham, P., Howard, K. and Ish-Horowicz, D. (1985). Transcription pattern of the segemtation gene hairy. Nature 318, 439-445.

Jimenez, J., Alphey, L., Nurse, P. and Glover, D. M. (1990). Complementation of fission yeast $c d c 2 t s$ and $c d c 25 t s$ mutants identifies two cell cycle genes from Drosophila: a $c d c 2$ homologue and string. EMBO J. 9, 3565-3571.

Kawasaki, E. S. (1990). Amplification of RNA, In PCR Protocols: A guide to Methods and Applications (ed. Innis M. A., Gelfand D. H., Sninsky, J. J. and White, T. J. ). pp21-27 London, Academic Press.

Klemenz, R., Weber, U. and Gehring, W. (1987). The white gene as a marker in a new P-element vector for gene transfer in Drosophila. Nuc. Acids Res. 15, 3947-3959.

Laski, F. A., Rio, D. C. and Rubin, G. M. (1986). Tissue specificity of Drosophila P-element transposition is regulated at the level of mRNA splicing. Cell 44, 7-19.

Lasko, P. F. and Ashburner, M. (1988). The product of the Drosophila gene vasa is very similar to eukaryotic initiation factor 4A. Nature $\mathbf{3 3 5}$, 611-617. 
Lee, M. and Nurse, P. (1987). Complementation used to clone a human homologue of the fission yeast cell cycle control gene $c d c 2$. Nature 327, 31-35.

Lehmann, R. and Nusslein-Volhard, C. (1986). Abdominal segmentation, pole cell formation and embryonic polarity require the localised activity of oskar, a maternal gene in Drosophila. Cell 47, 141152.

Lehner, C. and O'Farrell, P. H. (1989). Expression and function of Drosophila cyclin A during embryonic cell cycle progression. Cell $\mathbf{5 6}$, 957-968.

Lehner, C. and O'Farrell, P. H. (1990a). The role of Drosophila cyclins A and B in mitotic control. Cell 61, 535-547.

Lehner, C. and O'Farrell, P. H. (1990b). Drosophila cdc2 homologues: a functional homologue is coexpressed with a cognate variant. EMBO J. 9, 3571-3580

MacDonald, P. M. and Struhl, G. (1988). cis-Acting sequences responsible for anterior localisation of bicoid mRNA in Drosophila embryos. Nature 336, 595-598.

Mahowald, A. P. and Kambysellis, M. (1980). Oogenesis. In Genetics and Biology of Drosophila Vol 2d, (ed. Ashburner M. and Wright T.W.) pp141-209. London, Academic press.

Mahowald, A.P. (1968). Polar granules of Drosophila II. Ultrastructural changes during early embryogenesis. J. Exp. Zool. 167, 237-262.

Maldonado-Codina, G. and Glover, D. M. (1992). Cyclins A and B associate with chromatin and the polar regions of spindles respectively and do not undergo complete degradation at anaphase in syncytial Drosophila embryos. J. Cell Biol. (in press).

Manseau, L. J. and Schupbach, T. (1989). cappuccino and spire: two unique maternal effect loci required for both the anterio-posterior and dorso-ventral polarity of the Drosophila embryo. Genes Dev. 3, 14731452.

Meijer, L., Arion, D., Goldsteyn, R., Pines, J., Brizuela, L., Hunt T. and Beach D. (1989). Cyclin is a component of sea urchin egg M-phase specific histone $\mathrm{H} 1$ kinase. EMBO J. 8, 2275-2282.

Minshull, J., Blow, J. J. and Hunt, T. (1989). Translation of cyclin mRNA is necessary for extracts of activated Xenopus eggs to enter mitosis. Cell 56, 947-956.

Minshull, J., Golsteyn R., Hill, C. S. and Hunt, T. (1990). The A- and B- type cyclin associated $c d c 2$ kinases in Xenopus turn on and off at different times in the cell cycle. EMBO J. 9, 2865-2875.

Mitchison, T. and Sedat, J. T. (1983). Localisation of antigenic determinants in whole Drosophila embryos. Dev. Biol. 99, 261-264.

Moreno, S. and Nurse, P. (1990). Substrates for p34 ${ }^{\text {cdc2 }}$ : in vivo veritas ? Cell 61, 549-551

Mount, S. M. (1982). A catalogue of splice junction sequences. Nucleic Acids Res. 10, 459-472.

Murray, A. W. and Kirschner, M. W. (1989). Cyclin synthesis drives the early embryonic cell cycle. Nature 339, 275-280.

Murray, A. W., Solomon, M. J. and Kirschner, M. W. (1989). The role of cyclin synthesis and degradation in the control of maturation promoting factor activity. Nature 339, 280-286.

Nusslein-Volhard, C., Frohnhofer, H. G. and Lehmann, R. (1987). Determination of anterio-posterior polarity in Drosophila. Science $\mathbf{2 3 8}$, 1675-1681.
Parker, L. L., Atherton-Fessler, S., Lee, M., Ogg, S., Falk, J. M., Swenson, K. I. and Piwnica-Worms, H. (1991). Cyclin promotes tyrosine dephosphorylation of $c d c 2$ in a wee $^{+}$dependent manner. EMBO J. 10, 1255-1263.

Pines, J. and Hunt, T. (1987). Molecular cloning and characterisation of the mRNA for cyclin from sea urchin eggs. EMBO J. 6, 2987-2995.

Pines, J. and Hunter, T. (1989). Isolation of a human cyclin cDNA: Evidence for cyclin mRNA and protein regulation in the cell cycle and for interaction with $\mathrm{p} 34^{\mathrm{cdc} 2}$. Cell 58, 833-846.

Pines, J. and Hunter, T. (1990). Human cyclin A is adenovirus E1A associated p60 and behaves differently from cyclin B. Nature 346, 760763.

Pines, J. and Hunter, T. (1991). Human cyclins A and B1 are differentially located in the cell and undergo cell cycle-dependent nuclear transport. J. Cell Biol 115, 1-17.

Rabinowitz, M. (1941). Studies on the cytology and early embryology of the egg of Drosophila melanogaster. J. Morph. 69, 1-49.

Raff, J. W. and Glover, D. M. (1989). Centrosomes and not nuclei initiate pole cell formation in the Drosophila embryo. Cell 57, 611-619.

Raff, J. W., Whitfield, W. G. F. and Glover, D. M. (1990). Two distinct mechanisms localise cyclin B transcripts in syncytial Drosophila embryos. Development 110, 1249-1261.

Schupbach, T. and Wieschaus, E. (1986). Maternal effect mutations altering the anterior posterior pattern of the Drosophila embryo. Roux's Arch. Dev. Biol. 195, 302-317

Solomon, M. J., Booher, R., Kirschner, M. W. and Beach, D. (1988) Cyclin in fission yeast. Cell 54, 738-739.

St.Johnston, D., Driever, W., Berleth, T., Richstein, S. and NussleinVolhard, C. (1989). Multiple steps in the localisation of bicoid RNA to the anterior pole of the Drosophila oocyte. Development (suppl.) 107, 13-19.

Standart, N., Minshull, J., Pines, J. and Hunt, T. (1987). Cyclin synthesis, modification and destruction during meiotic maturation of the starfish oocyte. Dev. Biol 124, 248-258.

Swenson, K., Farrell, K. M. and Rudermann, J. V. (1986). The embryo protein cyclin A induces entry into M-phase and the resumption of meiosis in Xenopus oocytes. Cell 47, 861-870.

Tautz, D. and Pfeifle, C. (1989). A non-radioactive in situ hybridisation method for the localisation of specific mRNAs in the Drosophila embryo reveals translational control of the segmentation gene hunchback. Chromosoma 98, 81-85.

Westendorf, J. M., Swenson, K. I., and Rudermann, J. V. (1989). The role of cyclin B in meiosis I. J. Cell Biol. 108, 1431-1444.

Whitfield, W. G. F., Gonzalez, C., Maldonado-Codina, G. and Glover, D. M. (1990). The A and B type cyclins of Drosophila are accumulated and destroyed in temporally distinct events that define separable phases of the G2-M transition. EMBO J. 9, 2563-2572.

Whitfield, W. G. F., Gonzalez, C., Sanchez-Herrero, E. and Glover, D. M. (1989). Transcripts of one of two Drosophila cyclin genes become localised in pole cells during embryogenesis. Nature 338, 337-340. 